\title{
The Results of Core Decompression Treatment in Avascular Necrosis of the Femoral Head
}

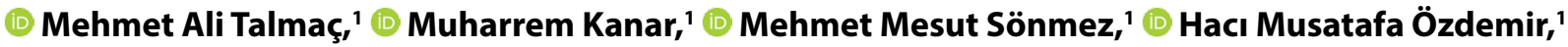 \\ (D) Ferdi Dırvar, ${ }^{2}$ (D) Yüksel Tenekecioğlü \\ 'Department Orthopedics and Traumatology, Şişli Hamidiye Etfal Training and Research Hospital, İstanbul, Turkey \\ ${ }^{2}$ Department Orthopedics and Traumatology, University of Health Sciences Metin Sabancı Baltalimanı Osteopathic Training and \\ Research Hospital, İstanbul, Turkey \\ ${ }^{3}$ Department Orthopedics and Traumatology, İstanbul University Cerrahpaşa Faculty of Medicine, İstanbul, Turkey
}

\begin{abstract}
Objective: Avascular necrosis of the femoral head (AVNFH) is a progressive disease seen in young, active patients, leaving significant disability in the joint when untreated. We retrospectively examined the results of patients with early stage AVNFH who had been operated in our clinic.

Methods: In our study, 65 hips of 46 patients were evaluated retrospectively. These patients were evaluated clinically by the Merle d'Aubigné-Postel Score and Harris Hip Score. The patients were radiologically staged according to the criteria by Ficat and Arlet with hip anterior-posterior and lateral graphs and magnetic resonance imaging.

Results: The mean follow-up period of the patient group was 73 months, and the mean age of the patients was 35 years. Of these patients, $59 \%$ were female and $41 \%$ were male; $41 \%$ had bilateral and $40 \%$ had right hip involvement. One of the patients developed AVNFH while she was pregnant, 7 were idiopathic, and 38 (81\%) developed AVNFH due to steroid use. According to the Ficat and Arlet classification, 18 hips were found to be stage 1, 37 hips stage 2, and 9 hips stage 3 during admission. From the etiological point of view, $81 \%$ of the patients developed AVNFH while using steroid and $19 \%$ had idiopathic AVNFH. As for clinical improvement of the patients, the Harris Hip Score increased from 58 to 90 in idiopathic patients and 55 to 83 among steroid users. The Merle d'Aubigné-Postel classification scores increased from 6 to 15 in the idiopathic group and from 6 to 13 among steroid users. Radiologically, according to the Ficat and Arlet stage, progression was seen in all stages. Of the patients, $38.8 \%$ in stage 1 , $70.2 \%$ in stage 2 , and $88.8 \%$ in stage 3 showed progression, whereas $20 \%$ demonstrated rapid progression and needed total hip prosthesis. All patients who demonstrated progression were on chronic steroid therapy. The mean time to conversion to total hip replacement was 27 months.

Conclusion: Osteonecrosis is a disease associated with high morbidity. Early diagnosis can reduce morbidity and improve a patient's quality of life. Core decompression has the effect of stopping the progression of AVNFH in the early (stage 1) stages, although it has a significant and long-term palliative effect in all stages. Most of the young and active patients with AVNFH still do not have any ideal method for treatment today, but core decompression in the early stages has been seen to reduce morbidity. It is a time-saving attempt before the final treatment, which is hip arthroplasty, is performed.
\end{abstract}

Keywords: Avascular necrosis; core decompression; femoral head.

Please cite this article as "Talmaç MA, Kanar M, Sönmez MM, Özdemir HM, Dırvar F, Tenekecioğlu Y. The Results of Core Decompression Treatment in Avascular Necrosis of the Femoral Head. Med Bull Sisli Etfal Hosp 2018;52(4):249-253."

Address for correspondence: Mehmet Ali Talmaç, MD. Sağlık Bilimleri Üniversitesi, Şişli Hamidiye Etfal Eğitim ve Araştırma Hastanesi,

Ortopedi ve Travmatoloji Kliniği, İstanbul, Turkey

Phone: +90 2123255125 E-mail: drtalmac2@gmail.com

Submitted Date: April 07, 2018 Accepted Date: April 25, 2018 Available Online Date: December 28, 2018

${ }^{\circ}$ Copyright 2018 by The Medical Bulletin of Sisli Etfal Hospital - Available online at www.sislietfaltip.org

This is an open access article under the CC BY-NC-ND license (http://creativecommons.org/licenses/by-nc/4.0/). 
A vascular necrosis of the femoral head (AVNFH) is a progressive disease that causes severe disability as a result of collapse of the joint surface due to the weakening of the subchondral bone, bone fracture, and apoptosis caused by a decrease or discontinuation of the blood supply to the femoral head. Although its etiopathogenesis is not clearly known, it is thought to be multifactorial. ${ }^{[1,2]}$ According to US data, risk factors for AVNFH are estimated to be associated with alcohol use in 20\%-40\%, steroid treatment in $35 \%-40 \%$, and idiopathic etiologies in 35\%-40\% of the cases. ${ }^{[3]}$ The disease mostly affects young active individuals between the ages of 30 and 50 years and poses serious socioeconomic problems for this population in their active business life. ${ }^{[4]}$ AVNFH is bilateral in $30 \%-70 \%$ of the cases. As reported in literature, its incidence in German-speaking countries is thought to be $0.01 \% .^{[5]}$ In the US, 20.000-30.000 new patients are diagnosed with avascular necrosis annually. Of the 250.000 total hip arthroplasties performed in 1 year, $10 \%$ are composed of coxarthrosis on the background of AVNFH. The disease rarely regresses spontaneously, and it progresses in $67 \%$ of untreated asymptomatic patients and $85 \%$ of symptomatic patients. ${ }^{[6]}$ Although most investigators have planned the treatment methods according to the patient's age, symptoms, stage of disease, and concomitant systemic disease, no algorithm has been established yet. ${ }^{[4,7]}$ In the early stages, core decompression surgery is thought to slow the progression of the disease and decrease the symptoms. Therefore, establishment of the diagnosis at an early stage has a critical importance.

With detailed anamnesis, physical examination appropriate radiological examination diagnosis can be made. ${ }^{[6]}$ AVNFH progressively causes coxarthrosis, and in these patients due to long-term problems of total hip arthroplasty. In the early stages of the disease, core decompression, which is one of the treatment methods used to protect the hip joint, can be applied. ${ }^{[8]}$ In our study, we evaluated the effectiveness of core decompression surgery in severely disabled young patients with early stage AVNFH.

\section{Methods}

In our clinic, 46 out of the 79 patients who underwent core decompression due to AVNFH between 1998 and 2009 were evaluated. Sixty-five hips of 46 patients were included in the study. Patients with Ficat-Arlet stage 4, with a history of total hip arthroplasty, or who had osteonecrosis developed on the background of trauma and children were excluded from the study. Patients were classified according to age, gender, laterality, bilaterality, and etiological factors. The patients were evaluated using the Ficat-Arlet staging based on preoperatively and postoperatively obtained anteroposterior radiograms and magnetic resonance imaging of the hips (Table 1). ${ }^{[9]}$ Functionally, patients were followed up with preoperative and postoperative Harris Hip Scores ${ }^{[10]}$ and Merle d'AubignéPostel staging ${ }^{[11]}$ (Table 2).

\section{Statistical Analysis}

Data were evaluated using SPSS Windows 10.0 statistical package program (SPSS Inc., Chicago, IL, USA). Wilcoxon rank, Mann-Whitney U, Paired Student's t and chi-square tests were used. Pearson correlation analysis was used for correlation of data. A p value $<0.05$ was considered significant. The study was conducted with the approval of the Ethics Committee (decision no. 11555).

Table 1. Ficat-Arlet staging system

\begin{tabular}{ll}
\hline Stage & Radiological findings \\
\hline I & $\begin{array}{l}\text { Plain radiograph, magnetic resonance imaging, and } \\
\text { scintigraphy: normal }\end{array}$ \\
IIA & $\begin{array}{l}\text { Sclerotic and cystic lesion (absence of subchondral } \\
\text { cystic formation) }\end{array}$ \\
IIB & $\begin{array}{l}\text { Subchondral collapse (crescent sign) and/or } \\
\text { subchondral aliasing } \\
\text { III }\end{array}$ \\
IV & $\begin{array}{l}\text { Irregular femoral contour } \\
\text { Collapse of the femoral head, acetabular involvement, } \\
\text { and articular destruction (osteoarthritis) }\end{array}$ \\
\hline
\end{tabular}

Table 2. Merle d'Aubigné-Postel Score

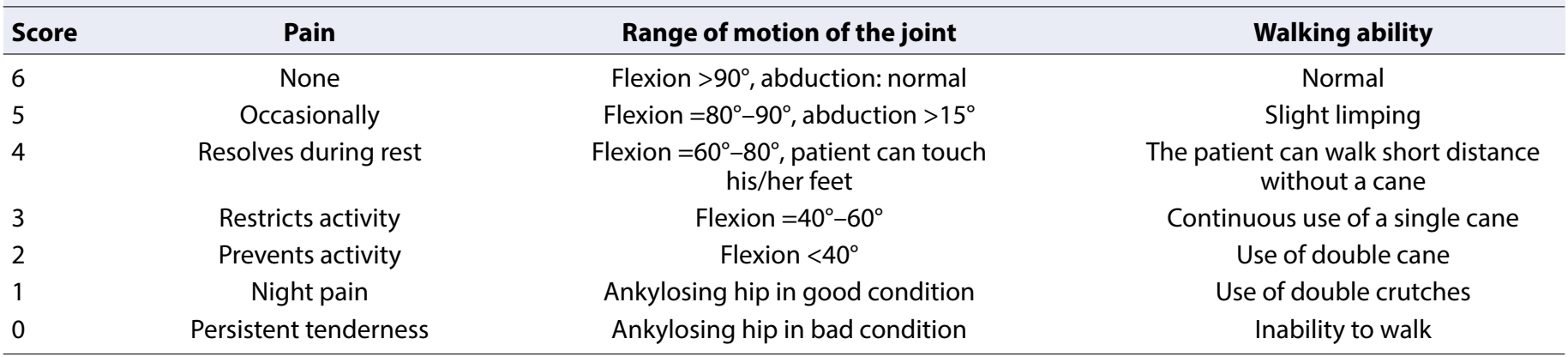

15-18 points, good; $12-14$ points, moderate; $<12$ points, bad. 


\section{Results}

The mean age of the patients was $35(20-58)$ years. Of the operated patients, 27 (59\%) were female, and 19 (41\%) were male. The mean follow-up period was 73 months. When the cases were evaluated according to the affected side, AVNFHs were right $(n=18 ; 39.1 \%)$ and left $(n=9 ; 19.6 \%)$ sided or bilateral $(n=19 ; 41.3 \%)$. AVNFH was due to chronic steroid use in 38 ( $n=53$ hips; 81.38\%), pregnancy-related complications in 1 (3.07\%), and idiopathic etiologies in 7 $(18.46 \%)$ patients (Table 3). Since the majority of the patients included in our study were referred from the rheumatology clinic of our university, steroid was the common etiologic agent. The lesions on the femoral head were radiologically classified according to the Ficat-Arlet criteria. According to the Ficat-Arlet staging, at admission, 18 hips were in stage 1, 37 hips in stage 2, and 9 hips in stage 3.

All patients underwent core decompression surgery. Fortysix patients (65 hips) were placed in supine position on the radiolucent table and underwent forage under the guidance of the scopy. These procedures were performed in the same session, except five patients with bilateral involvement. All patients underwent antibiotherapy for $24 \mathrm{~h}$ postoperatively. The patients were mobilized on day 2 with the help of crutches. Patients undergoing bilateral forages were followed up with bed exercises and pool therapy until week 6 when the load-bearing period began. The patients who were mobilized with crutches for 6 weeks without weight-bearing had an average hospital stay of 2 days.

Any additional treatments, such as antiresorptive medication and hyperbaric oxygen administration, were not given during the postoperative period. In general, during outpatient follow-ups, all patients were allowed to complete week 6 with partial weight-bearing, and then full weightbearing was permitted starting from month 3 . One patient developed subtrochanteric fracture following full weightbearing on postoperative month 3 (Fig. 1). None of the patients had deep infection, deep vein thrombosis, and bleeding. The mean follow-up period was 73.35 months. Patients were evaluated clinically and radiologically. Clinically, the
Table 3. Etyology

1. Idiopathic

7

15.2

2. Pregnancy-related

Related to steroid use;

3. SLE

4. ITP

10.9

5. Kidney transplantation

6. Pemphigus vulgaris

4.3

7. Temporal arteritis

8. NHL

4.3

9. Asthma

10. Hodgkin's lymphoma

4.3

11. Wegener's granulomatosis

2.2

12. Blepharitis

2.2

13. Myositis

14. Evans syndrome

15. Chronic bronchitis

16. Chronic pleurisy

17. Pseudotumor of orbita

18. ALL

19. Henoch-Schönlein purpura

Table 4. Pre and postoperative distributions of the Harris Hip classification scores

\begin{tabular}{llcllcr}
\hline \multirow{2}{*}{$\begin{array}{l}\text { Etiology } \\
\text { Harris }\end{array}$} & \multicolumn{2}{c}{ Idiopathic } & & \multicolumn{2}{c}{ Steroid } & \\
\cline { 2 - 3 } & Mean & SD & & Mean & SD & P \\
\hline Preop & 58.71 & 6.85 & & 55.24 & 5.04 & .136 \\
Postop & 89.86 & 10.99 & & 83.11 & 13.14 & .220 \\
Difference & 31.14 & 5.46 & & 28.04 & 12.06 & .514 \\
\hline
\end{tabular}

Harris Hip and Merle d'Aubigné-Postel Scores were rated. After clinical examination, magnetic resonance imaging was performed in all patients in addition to plain radiograms (pelvis anterior-posterior [AP] and hip AP/lateral) and staged according to the postoperative Ficat-Arlet criteria.

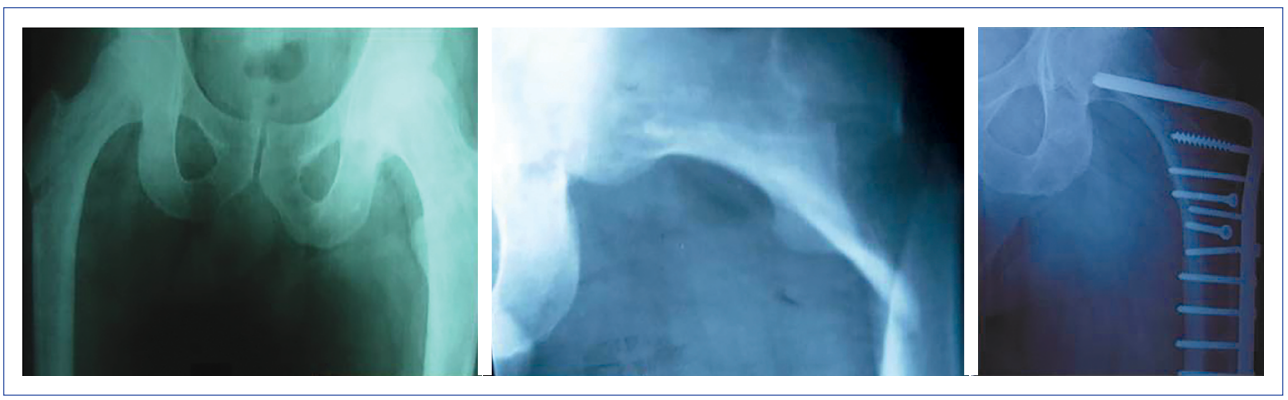

Figure 1. Proximal femur subtrochanteric fracture due to core decopression. 
Table 5. Pre and postoperative distributions of the Merle d'Aubigné-Postel classification scores

\begin{tabular}{lcccccc}
\hline \multirow{2}{*}{$\begin{array}{l}\text { Etyoloji } \\
\text { Merle }\end{array}$} & \multicolumn{2}{c}{ Idiopathic } & & \multicolumn{2}{c}{ Steroid } & \\
\cline { 2 - 3 } & Mean & SD & & Mean & SD & p \\
\hline Preop & 5.86 & .90 & & 5.62 & 1.08 & .597 \\
Postop & 15.43 & 2.44 & & 13.79 & 3.68 & .274 \\
Difference & 9.57 & 1.72 & & 8.17 & 3.55 & .321 \\
\hline
\end{tabular}

Table 6. Pre and postoperative disease progression in three stages according to the Ficat-Arlet classification

\begin{tabular}{lccccc}
\hline & \multicolumn{4}{c}{ Postop Ficat-Arlet } & \\
\cline { 2 - 5 } Preop Ficat & Stage 1 & Stage 2 & Stage 3 & Stage 4 & Total \\
\hline Stage 1 & 11 & 5 & 1 & 1 & 18 \\
Stage 2 & & 11 & 8 & 18 & 37 \\
Stage 3 & & & 1 & 8 & 9 \\
Total & 11 & 16 & 10 & 27 & 64 \\
\hline
\end{tabular}

The surgical outcomes of the patients who had been subjected to total hip arthroplasty were evaluated at the final follow-up visit according to the Harris Hip Scores as excellent in 24 , good in 11 , moderate in 5 , and poor in 4 hips and as good in 28, moderate in 15, and poor in 3 hips based on the Merle d'Aubigné-Postel Scores. In our cases, the Harris Hip Score and Merle d'Aubigné-Postel Scores were found to be statistically significantly correlated with each other, and clinical findings and improvements were also statistically significant. However, any statistically significant difference was not seen between patients using and not using steroid therapy (Table 4, 5). However, AVNFH in $64 \%$ of the patients in the steroid-treated and systemic lupus erythematosus (SLE) groups progressed rapidly so total hip prosthesis was applied.

According to the Ficat-Arlet staging system based on radiological and clinical findings, progression was seen in $38.8 \%, 70.2 \%$, and $88.8 \%$ of the patients in stages 1,2 , and 3 , respectively (Table 6).

In the present study, there are no correlation between the clinical and radiological stages of the disease. In our study, clinical improvement was observed in patients who showed radiologically progressive disease.

Thirteen out of the 65 hips (20\%) subjected to core decompression because of AVNFH showed rapid deterioration that required total hip prosthesis The mean time to total hip replacement was 27.6 (15-41) months.

\section{Discussion}

A consensus on the treatment of AVNFH has not yet been established. ${ }^{[12,13]}$ The treatment is planned according to the stage of the disease, its etiology, duration of symptoms, pain, and systemic disease. Patients with AVNFH develop subchondral fracture within 2-3 years if not treated, and joint-conserving surgery cannot be performed.$^{[5]}$ In AVNFH, core decompression is thought to decrease blood pressure in the femoral head by decreasing the pressure in the early stage and conversion to implantation of total hip prosthesis and pain. ${ }^{[4,14]}$

Ficat ${ }^{[9]}$ presented core decompression for the first time in 1962. This procedure is intended to increase the blood supply to the necrotic area by means of a drill hole made from the distal end of the trochanter. In addition to core decompression therapy, there are also graft (vein-veinless fibula), mesenchymal stem cell, and tantalum rod applications. ${ }^{[15,}$ ${ }^{16]}$ Core decompression is still the preferred procedure because it is simpler than other methods, and the complication is low. The most common complication of this method is proximal femur fracture, which is reported to range between $0 \%$ and $18 \%{ }^{[17]}$ (Fig. 1). In our series, 1 (3\%) patient had subtrochanteric fracture. We think that the complication rate is due to the development of the technique and the progression of postoperative rehabilitation. ${ }^{[18]}$ AVNFH shows higher rates of bilateral joint involvement in 30\%$70 \%$ of the cases ${ }^{[5]}$ In our series, bilateral joint involvement was observed in $40 \%$ of these cases. For this reason, both hips of the patients should be examined. Mont et al. ${ }^{[19]} \mathrm{com}$ piled the outcomes of 1206 cases with AVNFH reported in the literature up to now and revealed that forage exerts a significant positive effect on the course of the disease and increases survival rates in stages 1 and 2 from $35 \%$ to $85 \%$ and from $31.4 \%$ to $65 \%$, respectively, compared with conservative treatment. As shown in our study, forage cannot prevent radiological progression, and progression rates reached $38.8 \%, 70.2 \%$, and $88.8 \%$ in stages 1,2 , and 3 , respectively. Fairbank et al. ${ }^{[8]}$ reported these rates as $62 \%$ and $93 \%$, respectively.

Disease progression was also seen in our stage 1 patients. AVNFH induced by steroid use seen in $80 \%$ of the patients was associated with different follow-up periods of the patients.

The effect of forage on stopping the progression of AVNFH is evident only in the early stage (stage $1 / 2$ ) lesions but has a marked and long-lasting analgesic effect in all stages. ${ }^{[20]}$ Similarly, in a meta-analysis performed by Castro and Barrack, ${ }^{[17]} 22$ relevant publications on core decompression were compared with 8 publications on conservatively treated patients. As a result, it was shown that core decompression was superior to conservative treatment only when applied to stage 1 lesions.

When we evaluated our results, a significant progression 
was observed between stage 1 and stage 2-3 cases. Our study was consistent with the study by Castro and Barrak. In contrast to the literature, the progression of stage 1 disease was attributed to SLE and steroid use in the patient group. When the femoral head collapses and the acetabulum is affected, the treatment option is joint reconstruction. The most common method performed is total hip arthroplasty and surface replacement. The preference of these methods depends on the stage and extent of the disease. ${ }^{[21]}$ Thirteen out of the 65 hips of our cases showed progression after core decompression, so total hip replacement was performed.

The effect of core decompression on the progression of AVNFH is evident in radiological and clinical early stage (stage 1) lesions, whereas it has a marked and long-lasting analgesic effect at all stages. Since an ideal method for the treatment of most of the young and active patients with AVNFH has not been found, core decompression is a timesaving intervention prior to total arthroplasty with important analgesic effects. Considering that the aim of the treatment of AVNFH is to obtain a painless and functional hip, this treatment method can be said to be clinically successful at an early stage.

\section{Disclosures}

Ethics Committee Approval: The study was conducted with the approval of the Ethics Committee (decision no. 11555).

Peer-review: Externally peer-reviewed.

Conflict of Interest: The authors declare no conflict of interest. Authorship contributions: Concept - M.A.T.; Design - Y.T.; Supervision - M.K.; Materials - M.A.T.; Data collection \&/or processing - M.A.T.; Analysis and/or interpretation - M.M.S..; Literature search - F.D.; Writing - M.A.T.; Critical review - H.M.Ö.

\section{References}

1. Herndon JH, Aufranc OE. Avascular necrosis of the femoral head in the adult. A review of its incidence in a variety of conditions. Clin Orthop Relat Res 1972;86:43-62. [CrossRef]

2. Mwale $\mathrm{F}$, Wang $\mathrm{H}$, Johnson AJ, Mont MA, Antoniou J. Abnor-mal vascular endothelial growth factor expression in mesenchymalstem cells from both osteonecrotic and osteoarthritic hips. Bull NYU Hosp Jt Dis 2011;69:S56-61.

3. Bradway JK, Morrey BF. The natural history of the silent hip in bilateral atraumatic oste-onecrosis. J Arthroplasty 1993;8:383-7. [CrossRef]

4. Lieberman JR, Berry DJ, Mont MA, Aaron RK, Callaghan JJ, Rajadhyaksha $A D$, et al. Osteonecrosis of the hip: management in the 21st century. Instr Course Lect 2003;52:337-55.

5. Arbab D, König DP. Atraumatic Femoral Head Necrosis in Adults.
Dtsch Arztebl Int 2016;113:31-8. [CrossRef]

6. Moya-Angeler J, Gianakos AL, Villa JC, Ni A, Lane JM. Current concepts on osteonecro-sis of the femoral head. World J Orthop 2015;6:590-601. [CrossRef]

7. Mont MA, Jones LC, Sotereanos DG, Amstutz HC, Hungerford DS. Understanding and treating osteonecrosis of the femoral head. Instr Course Lect 2000;49:169-85.

8. Fairbank AC, Bhatia $D$, Jinnah $\mathrm{RH}$, Hungerford DS. Long-term results of core decompres-sion for ischaemic necrosis of the femoral head. J Bone Joint Surg Br 1995;77:42-9. [CrossRef]

9. Ficat RP. Idiopathic bone necrosis of the femoral head. Early diagnosis and treatment. J Bone Joint Surg Br 1985;67:3-9. [CrossRef]

10. Harris WH. Traumatic arthritis of the hip after dislocation and acetabularfractures: treatment by mold arthroplasty. An end-result studyusing a new method of result evaluation. J Bone Joint Surg Am 1969;51:737-55. [CrossRef]

11. D'AUBIGNE RM, POSTEL M. Function-al results of hip arthroplasty with acrylic prosthesis. J Bone Joint Surg Am 1954;36-A:451-75.

12. Hernigou P, Manicom O, Poignard A, Nogier A, Filippini P, De Abreu L. Core decom-pression with marrow stem cells. Oper Tech Orthop 2004;14:68-74. [CrossRef]

13. Steinberg ME, Larcom PG, Strafford B, Hosick WB, Corces A, Bands $\mathrm{RE}$, et al. Core decompression with bone grafting for osteonecrosis of the femoral head. Clin Orthop Relat Res 2001;386:71-8. [CrossRef]

14. Urbaniak JR, Coogan PG, Gunneson EB, Nunley JA. Treatment of osteonecrosis of the femoral head with free vascularized fibular grafting. A long-term follow-up study of one hun-dred and three hips. J Bone Joint Surg Am 1995;77:681-94. [CrossRef]

15. Plancher KD, Razi A. Management of osteonecrosis of the femoral head. Orthop Clin North Am 1997;28:461-77. [CrossRef]

16. Nadeau M, Séguin C, Theodoropoulos JS, Harvey EJ. Short term clinical outcome of a porous tantalum implant for the treatment of advanced osteonecrosis of the femoral head. Mcgill J Med 2007;10:4-10.

17. Castro FP Jr, Barrack RL. Core decompression and conservative treatment for avascular necrosis of the femoral head: a metaanalysis. Am J Orthop (Belle Mead NJ) 2000;29:187-94.

18. Marker DR, Seyler TM, Ulrich SD, Srivastava S, Mont MA. Do modern techniques im-prove core decompression outcomes for hip osteonecrosis? Clin Orthop Relat Res 2008;466:1093-103. [CrossRef]

19. Buckwalter JA, Einhorn TA, Simon SR. Orthopaedic Basic Science: Biology and Biome-chanics of the Musculoskeletal System. Rosemont. American Academy Orthopaedic Sur-geons; 2000. p.19-76.

20. Aydoğdu S, Gümüşdağ H, Sır H. The role of core decompression in the treatment of avas-cular necrosis of the femoral head. Acta orthop traumatol turc 1997;31:90-3.

21. Saito S, Saito M, Nishina T, Ohzono K, Ono K. Long-term results of total hip arthroplasty for osteonecrosis of the femoral head. A comparison with osteoarthritis. Clin Orthop Relat Res 1989;244:198-207. 